\title{
Early versus late initiation of renal replacement therapy impacts mortality in patients with acute kidney injury post cardiac surgery: a meta-analysis
}

Honghong Zou ${ }^{1,3+}$, Qianwen Hong ${ }^{2+}$ and Gaosi $X^{3^{*}}$

\begin{abstract}
Background: Acute kidney injury (AKI) is a common clinical complication of cardiac surgery and increases mortality and hospitalization. We aimed to explore and perform an updated meta-analysis of qualitative and quantitative evaluations of the relationship between early renal replacement therapy (RRT) and mortality.

Methods: We searched the Chinese Biomedical Database, the Cochrane Library, EMBASE, Global Health, MEDLINE and PubMed.

Results: Fifteen studies (five randomized controlled trials (RCTs), one prospective cohort and nine retrospective cohorts) including 1479 patients were identified for detailed evaluation. The meta-analysis suggested that early RRT initiation reduced 28-day mortality (odds ratio (OR) 0.36; $95 \%$ confidence interval (CI) 0.23 to $0.57 ; P^{2} 60 \%$ ), and shortened intensive care unit (ICU) length of stay (LOS) (mean difference (MD) $-2.50 ; 95 \% \mathrm{Cl}-3.53$ to $-1.47 ; P^{2} 88 \%$ ) and hospital LOS (MD $-0.69 ; 95 \% \mathrm{Cl}-1.13$ to $-0.25 ; P^{2} 88 \%$ ), and also reduced the duration of RRT (MD $-1.18 ; 95 \%$ $\mathrm{Cl}-2.26$ to $-0.11 ; P^{2} 69 \%$ ), especially when RRT was initiated early within 12 hours (OR $0.23 ; 95 \% \mathrm{Cl} 0.08$ to 0.63 ; $P^{2} 73 \%$ ) and within 24 hours (OR $0.52 ; 95 \% \mathrm{Cl} 0.28$ to $0.95 ; P^{2}$ 58\%) in patients with AKI after cardiac surgery.

Conclusions: Early RRT initiation decreased 28-day mortality, especially when it was started within 24 hours after cardiac surgery in patients with AKl.
\end{abstract}

Keywords: Acute kidney injury, Cardiac surgery, Renal replacement therapy, Mortality, Early

\section{Background}

Acute kidney injury (AKI) as a complication following cardiac surgery is considered axiomatic and occurs in up to $45 \%$ of patients [1]. Although surgical, anesthetic and critical care advancements might efficiently decrease perioperative mortality and shorten intensive care unit (ICU) length of stay (LOS), it has not been confirmed in the reduction of the incidence of AKI, which increases the demand for postoperative renal replacement therapy (RRT) [2-4]. The initiation of RRT due to AKI has steadily increased over the past 15 years, which to some

\footnotetext{
*Correspondence: gaosixu@163.com

${ }^{\dagger}$ Equal contributors

${ }^{3}$ Department of Nephrology, the Second Affiliated Hospital of Nanchang University, No. 1, Minde Road, Donghu District, Nanchang 330006, People's Republic of China

Full list of author information is available at the end of the article
}

extent has enabled patients to survive longer [5-7], and decreased in-hospital mortality after surgeries [8-10]. Despite this, mortality due to AKI after cardiac surgery is an urgent problem to be solved, which presents challenges in clinical practice $[11,12]$.

Several meta-analyses relevant to this theme have been published in the past few years [13-16], which show the survival advantage of early initiation of RRT and recommend it for patients with AKI who undergo cardiac surgery, but there are some limitations in these studies; for instance, not all the referenced studies were based on cardiac surgery [14-16]. Furthermore, there were four further original studies [17-20] that were missed in the review by Liu et al. [13], which have been investigated in the present study. 
To address these knowledge gaps, we conducted a new meta-analysis to update the present ones and provide the evidence to guide clinicians on this important issue. Furthermore, we categorized the definition of early and late RRT by time cutoffs, and examined some other clinical outcomes, e.g. the relationship between the modality of RRT and mortality. We specifically aimed to explore the impact of the time of starting early RRT on mortality in patients with AKI post cardiac surgery.

\section{Methods}

\section{Search strategy}

We searched the Chinese Biomedical Database, the Cochrane Library, EMBASE, Global Health, MEDLINE and PubMed for articles from November 1971 to August 2016. The predefined key search terms included "cardiac surgery" or "coronary artery surgery" or "coronary artery bypass grafting" or "cardiopulmonary bypass", and "acute kidney injury" or "acute kidney failure" or "acute renal injury", and "renal replacement therapy" or "hemodialysis", and "early" or "late" or "time". We reviewed the related research references at the same time.

\section{Study criteria}

The inclusion criteria for studies were: (1) original research that related to early RRT initiation in adult patients with AKI after cardiac surgery, (2) articles that provided exact data on mortality in AKI and (3) articles that reported a clear comparison of early versus late RRT initiation with a direct effect on mortality. The exclusion criteria were: (1) duplication, (2) studies such as systemic reviews, meta-analyses, comments, case reports, animal experimental studies etc. and (3) studies of patients with pre-existing renal disease or who received RRT before undergoing cardiac surgery.

\section{Data extraction}

Early and late RRT were defined on the basis of different criteria reported by the authors in their original research; we accepted a broad definition of early and late RRT and categorized this by time cutoffs (e.g., within a defined time after cardiac surgery, or development of urine output or a biochemical "start time" such as serum creatinine and blood urea levels etc.). The fifteen articles were divided into five groups according to early RRT initiation within 12 hours, within 24 hours, within 48 hours, within 72 hours or unclassified. Also, we summarized AKI diagnosis in the included articles and classified them on the basis of the 2012 Kidney Disease: Improving Global Outcomes (KDIGO) criteria. We intended to optimize the potential for identifying an effect associated with early or late RRT and to explore whether there is a relationship between the timing of starting early RRT and mortality after cardiac surgery with AKI. The modality of RRT was hemodialysis.

Data were extracted independently by two investigators ( $\mathrm{HZ}$ and $\mathrm{QH})$. All potentially eligible citations that we searched were studied in detail to identify studies that satisfied the criteria. To identify duplicate records pertaining to a single study, we considered the PubMed database to take precedence; the details of the selection process are shown in Fig. 1. There would be a debate to reach consensus when there were disagreements. Data extraction included the first author's name, year of publication, study design, RRT modality, definition of early and late RRT, number of patients, number of deaths due to AKI in post cardiac surgery, the mean and standard deviation or median of the ICU LOS,

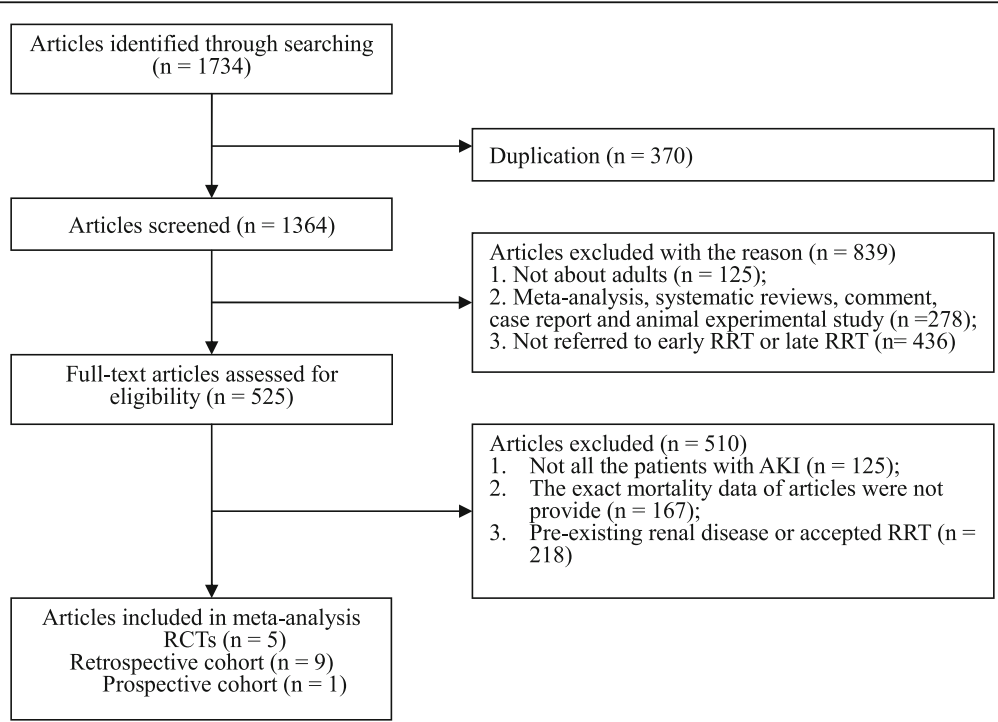

Fig. 1 Study selection process. RCT randomized controlled trial, RRT renal replacement therapy, AKI acute kidney injury 


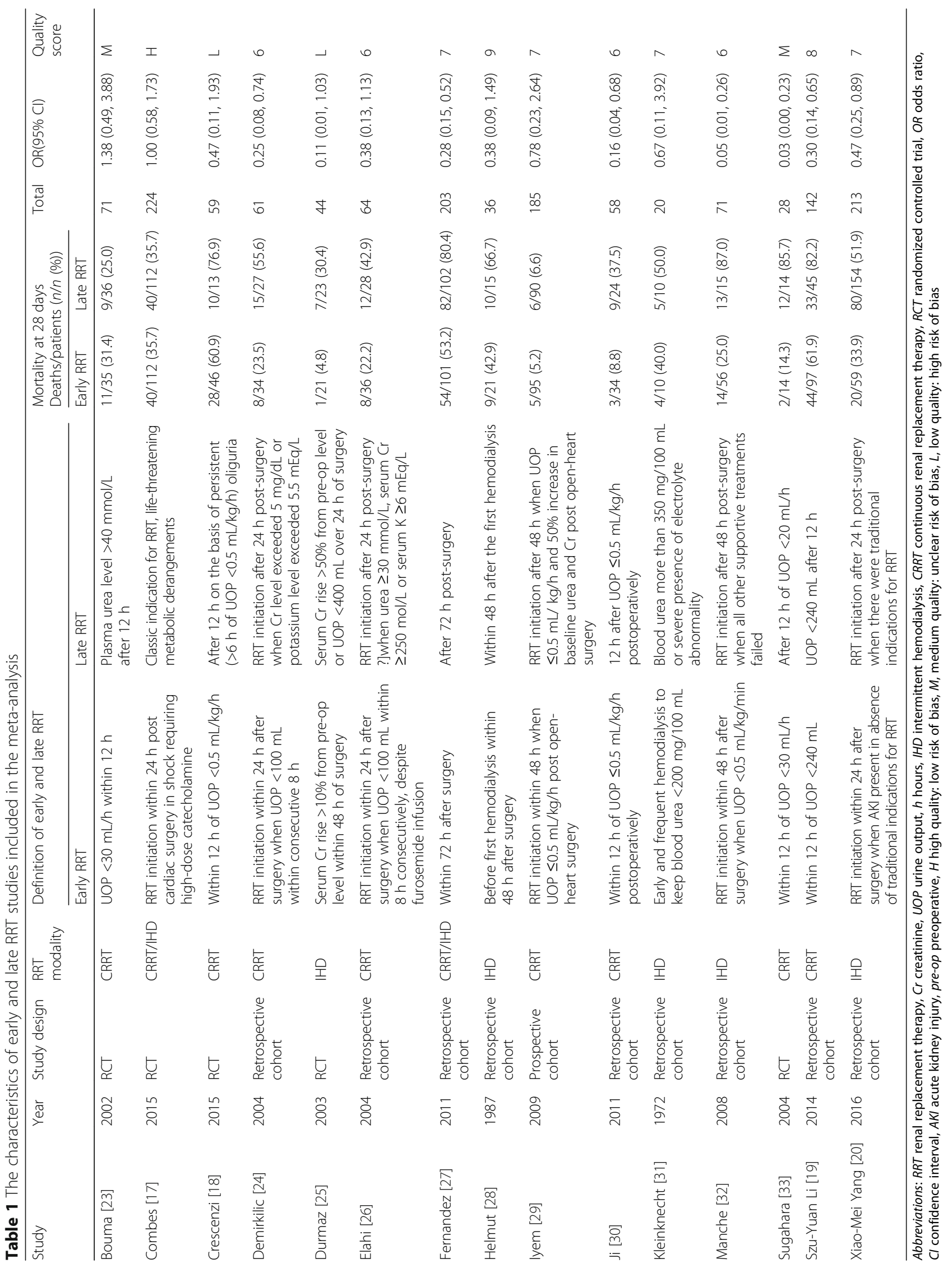


Table $\mathbf{2}$ Outcomes of early versus late RRT in patients with AKI after cardiac surgery

\begin{tabular}{|c|c|c|c|c|c|c|c|c|}
\hline \multirow[t]{2}{*}{ Study } & \multicolumn{2}{|c|}{ ICU LOS (days) } & \multicolumn{2}{|c|}{ Hospital LOS (days) } & \multicolumn{2}{|c|}{ Duration of RRT (days) } & \multicolumn{2}{|c|}{ Mechanical ventilation time (days) } \\
\hline & Early & Late & Early & Late & Early & Late & Early & Late \\
\hline Bouman [23] & $13 \pm 1.0$ & $13.5 \pm 1.5$ & 27.0 & 35.5 & 3.9 & 2.9 & 1.0 & 12.0 \\
\hline Combes [17] & NR & $N R$ & NR & NR & NR & NR & NR & NR \\
\hline Crescenzi [18] & $2.6 \pm 5.5$ & $2.2 \pm 3.4$ & $8.6 \pm 7.7$ & $8.2 \pm 5.5$ & NR & NR & NR & NR \\
\hline Demirkilic [24] & $7.9 \pm 1.3$ & $12.4 \pm 3.4$ & $15.4 \pm 4.0$ & $20.9 \pm 2.0$ & $4.3 \pm 1.5$ & $4.6 \pm 1.3$ & $1.0 \pm 0.6$ & $3.0 \pm 2.1$ \\
\hline Durmaz [25] & $1.6 \pm 0.9$ & $3.6 \pm 2.9$ & $8.9 \pm 2.6$ & $11.7 \pm 4.8$ & NR & NR & NR & NR \\
\hline Elahi [26] & $8.5 \pm 2.1$ & $12.5 \pm 5.3$ & $15.4 \pm 4.8$ & $20.9 \pm 7.3$ & $4.6 \pm 2.0$ & $4.6 \pm 11.4$ & NR & NR \\
\hline Fernandez [27] & $15.3 \pm 15.4$ & $27.9 \pm 24.4$ & $25.4 \pm 28.6$ & $38.2 \pm 33.2$ & $7.9 \pm 10.7$ & $12.5 \pm 17.5$ & $7.1 \pm 9.8$ & $10.7 \pm 18.6$ \\
\hline Helmut [28] & NR & NR & NR & NR & NR & NR & NR & $N R$ \\
\hline lyem [29] & $1.9 \pm 1.0$ & $3.7 \pm 0.7$ & $11.1 \pm 4.6$ & $17.1 \pm 5.6$ & NR & NR & $0.8 \pm 0.6$ & $0.8 \pm 0.5$ \\
\hline Ji [30] & $5.0 \pm 2.0$ & $8.0 \pm 2.0$ & $13.0 \pm 4.0$ & $18.0 \pm 6.0$ & $2.4 \pm 0.8$ & $4.1 \pm 1.1$ & NR & $N R$ \\
\hline Kleinknecht [31] & NR & $N R$ & NR & NR & NR & NR & NR & NR \\
\hline Manche [32] & NR & NR & NR & $N R$ & NR & NR & NR & $N R$ \\
\hline Sugahara [33] & NR & $N R$ & NR & NR & NR & NR & NR & NR \\
\hline Szu-Yuan Li [19] & 8.0 & 17.0 & 10.0 & 29.0 & 4.0 & 12.0 & NR & NR \\
\hline Xiao-Mei Yang [20] & 12.5 & 14.0 & $38.0 \pm 48.5$ & $31.5 \pm 33.0$ & $6.6 \pm 6.4$ & $7.6 \pm 7.4$ & 7.3 & 8.5 \\
\hline
\end{tabular}

Data are reported as mean \pm standard deviation or median. Abbreviations: RRT renal replacement therapy, AKI acute kidney injury, ICU intensive care unit, LOS length of stay, NR not reported

hospital LOS, duration of RRT and mechanical ventilation time: details are presented in Tables 1 and 2.

\section{Quality assessment}

The assessment of study quality for the randomized controlled trials (RCTs) was performed using Review Manager (version 5.3) risk-of-bias tool, including four sections: selection, performance/detection, attrition and reporting bias (Fig. 2). The Newcastle-Ottawa Scale (NOS) (range $0-9$ stars) was used to evaluate the cohort study quality (Table 1). For cohort studies, stars are awarded after evaluation of the three main categories of selection, comparability and outcomes: a study can be awarded no more than one star for each numbered option within the selection and exposure categories and no more than two stars can be awarded for comparability [21].

\section{Statistical analysis}

The data were abstracted and analyzed using Review Manager (version 5.3) and STATA statistical software (version 12.0) to make the outcomes more comprehensive. Estimation of effect was performed using a random-effects model and was summarized by forest plot, with data expressed as odds ratio (OR) with 95\% confidence interval (CI) for dichotomous outcomes and mean difference (MD) with 95\% CI for continuous outcomes. A random-effects model was used to deal with data in light of the heterogeneity in the results and the clinical characteristics of the study, while a fixed-effects model was used when there was poor heterogeneity. Heterogeneity was evaluated by the $Q$ statistic and $I^{2}$ tests, and low, moderate, and high heterogeneity was represented by thresholds of $<25 \%, 25-75 \%$, and $>75 \%$, respectively [22]. $P \leq 0.05$ was considered significant in all statistical tests. Subgroup and sensitivity analyses were used to explore the potential sources of heterogeneity. Egger and Begg test funnel plots were used to assess publication bias and the differences in the studies. Metaregression was used to test the influence of baseline characteristics as potential effect modifiers, and the variables, including the year of publication, study design, RRT modality, definitions of early and late RRT, late RRT mortality rate $\geq 50 \%$ and classification of AKI.

\section{Results}

\section{Description of included studies}

Fifteen trials [17-20, 23-33] with a total of 1479 patients (771 patients receiving early RRT versus 708 patients receiving late RRT) ultimately met our criteria (Table 1 ); these included five RCTs [17, 18, 23, 25, 33], one prospective cohort study [29] and nine retrospective cohort studies [19, 20, 24, 26-28, 30-32]. The characteristics and methodological quality of all the included studies are shown in Table 1 and the outcomes in patients with AKI after cardiac surgery are shown in Table 2. Ten of the included articles were evaluated for study quality based on the assessment of the NOS [19, 20, 24, 26-32].

\section{Effect of early RRT on mortality}

The effect of lower mortality was obvious in patients with AKI who underwent cardiac surgery and who received early RRT compared to patients who received late 


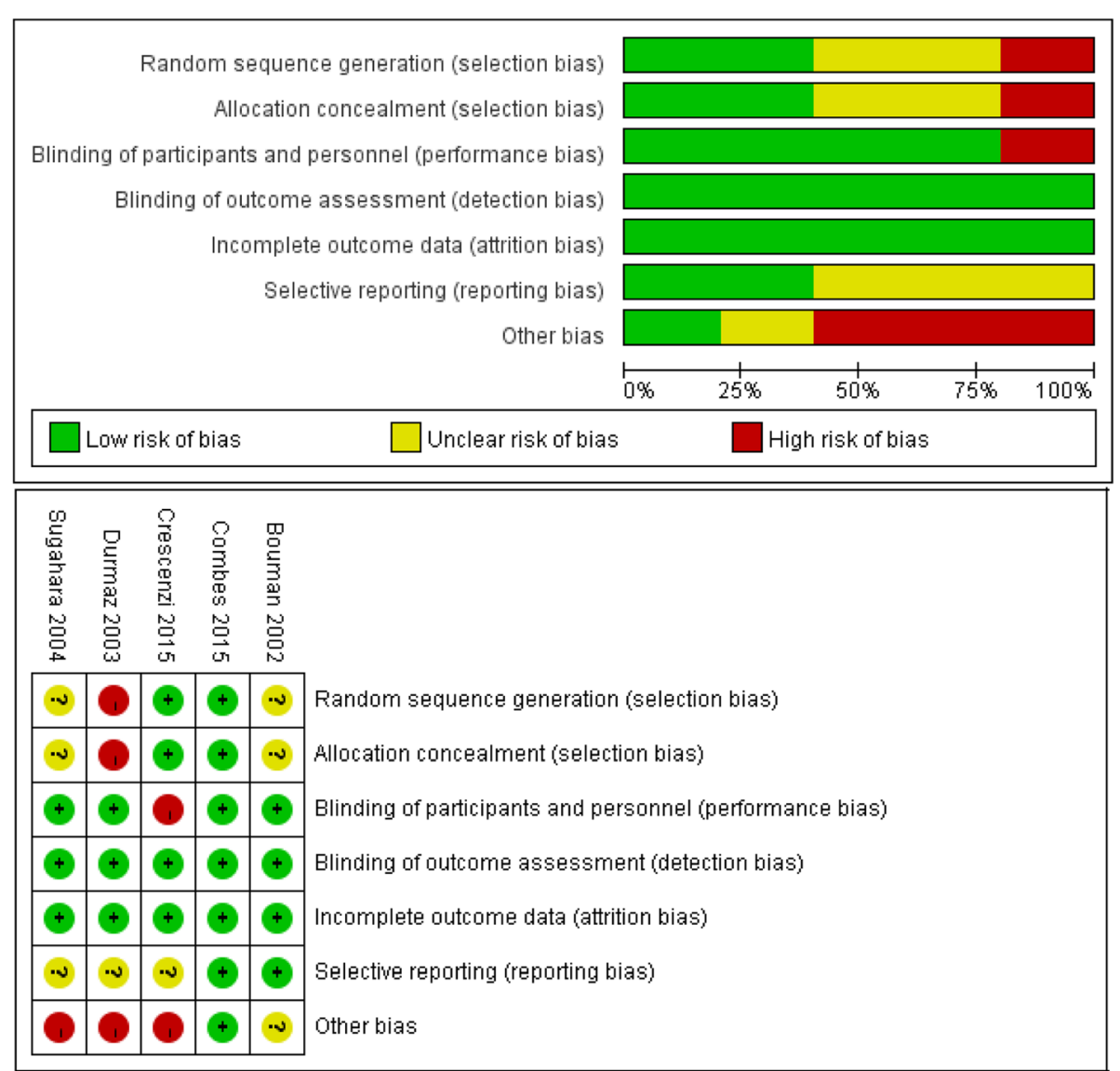

Fig. 2 Risk of bias and summary of risk of bias

\begin{tabular}{|c|c|c|c|c|c|c|c|c|c|c|}
\hline Study or Subgroup & $\begin{array}{c}\text { Early } \\
\text { Events }\end{array}$ & $y$ & \multicolumn{2}{|c|}{ Late } & Weight & $\begin{array}{c}\text { Odds Ratio } \\
\text { M-H, Random. } 95 \% \mathrm{Cl}\end{array}$ & \multicolumn{4}{|c|}{$\begin{array}{c}\text { Odds Ratio } \\
\text { M-H, Random, } 95 \% \mathrm{Cl} \\
\end{array}$} \\
\hline Bouman 2002 & 11 & 35 & 9 & 36 & $7.5 \%$ & $1.38[0.49,3.88]$ & & & & \\
\hline Combes 2015 & 40 & 112 & 40 & 112 & $10.7 \%$ & $1.00[0.58,1.73]$ & & & - & \\
\hline Crescenzi 2015 & 28 & 46 & 10 & 13 & $5.5 \%$ & $0.47[0.11,1.93]$ & & & & \\
\hline Demirkilic 2004 & 8 & 34 & 15 & 27 & $7.1 \%$ & $0.25[0.08,0.74]$ & & & & \\
\hline Durmaz 2003 & 1 & 21 & 7 & 23 & $3.0 \%$ & $0.11[0.01,1.03]$ & & & & \\
\hline Elahi 2004 & 8 & 36 & 12 & 28 & $7.2 \%$ & $0.38[0.13,1.13]$ & & & & \\
\hline Fernandez 2011 & 54 & 101 & 82 & 102 & $10.2 \%$ & $0.28[0.15,0.52]$ & & $\longrightarrow$ & & \\
\hline Helmut 1987 & 9 & 21 & 10 & 15 & $5.7 \%$ & $0.38[0.09,1.49]$ & & & & \\
\hline lyem 2009 & 5 & 95 & 6 & 90 & $6.4 \%$ & $0.78[0.23,2.64]$ & & & & \\
\hline Ji 2011 & 3 & 34 & 9 & 24 & $5.4 \%$ & $0.16[0.04,0.68]$ & & & & \\
\hline Kleinknecht 1972 & 4 & 10 & 5 & 10 & $4.2 \%$ & $0.67[0.11,3.92]$ & & & & \\
\hline Manche 2008 & 14 & 56 & 13 & 15 & $4.7 \%$ & $0.05[0.01,0.26]$ & & & & \\
\hline Sugahara 2004 & 2 & 14 & 12 & 14 & $3.2 \%$ & $0.03[0.00,0.23]$ & & & & \\
\hline Szu-Yuan Li 2014 & 44 & 97 & 33 & 45 & $9.2 \%$ & $0.30[0.14,0.65]$ & & & & \\
\hline Xiao-Mei Yang 2016 & 20 & 59 & 80 & 154 & $10.2 \%$ & $0.47[0.25,0.89]$ & & & & \\
\hline Total $(95 \% \mathrm{Cl})$ & & 771 & & 708 & $100.0 \%$ & $0.36[0.23,0.57]$ & & & & \\
\hline Total events & 251 & & 343 & & & & & & & \\
\hline $\begin{array}{l}\text { Heterogeneity: } \mathrm{Tau}^{2}= \\
\text { Test for overall effect: }\end{array}$ & $\begin{array}{l}0.39 ; \mathrm{Chi}^{2} \\
\mathrm{Z}=4.51(\mathrm{~F}\end{array}$ & $\begin{array}{l}=35.2 \\
0 \leq 0.00\end{array}$ & $\begin{array}{l}9, d f=14 \\
0001)\end{array}$ & $(P=0$ & $(.001) ;\left.\right|^{2}=$ & $=60 \%$ & 0.005 & $\begin{array}{l}0.1 \\
\text { Favors Early }\end{array}$ & $\begin{array}{cc}1 & 10 \\
& \text { Favors Late }\end{array}$ & 200 \\
\hline
\end{tabular}


Table 3 Meta-analysis of outcomes of early versus late RRT in patients with AKI post cardiac surgery

\begin{tabular}{|c|c|c|c|c|c|c|}
\hline Outcomes or subgroup analysis & Studies & Study reference number & Patients & OR/MD (95\% Cl) & $r^{2}$ & $P$ \\
\hline \multicolumn{7}{|c|}{ Primary outcomes: the effect of early versus late RRT on mortality } \\
\hline Mortality at 28 days & 15 & {$[17-20,23-33]$} & 1479 & $0.36(0.23,0.57)]$ & $60 \%$ & $<0.01$ \\
\hline \multicolumn{7}{|c|}{ Secondary outcomes: the relationship between early versus late RRT and mortality } \\
\hline ICU LOS & 8 & {$[18,23-27,29,30]$} & 745 & MD $-2.50(-3.53,-1.47)$ & $88 \%$ & $<0.01$ \\
\hline Hospital LOS & 8 & {$[18,20,24-27,29,30]$} & 887 & MD $-0.69(-1.13,-0.25)]$ & $88 \%$ & 0.002 \\
\hline Duration of RRT & 5 & {$[20,24,26,27,30]$} & 599 & MD -1.18 $(-2.26,-0.11)$ & $69 \%$ & 0.03 \\
\hline \multicolumn{7}{|c|}{ Subgroup analysis: the effect of the time of starting early RRT on mortality } \\
\hline RRT initiation within $12 \mathrm{~h}$ & 6 & {$[18,19,23,30,32,33]$} & 429 & $0.23(0.08,0.63)$ & $73 \%$ & 0.005 \\
\hline RRT initiation within $24 \mathrm{~h}$ & 4 & {$[17,20,24,26]$} & 562 & $0.52(0.28,0.95)$ & $58 \%$ & 0.03 \\
\hline RRT initiation within $48 \mathrm{~h}$ & 3 & {$[25,28,29]$} & 265 & $0.43(0.17,1.09)$ & $15 \%$ & 0.08 \\
\hline \multicolumn{7}{|c|}{ Subgroup analysis: the relationship between RRT modality and mortality } \\
\hline CRRT & 8 & {$[18,19,23,24,26,29,30,33]$} & 668 & $0.36(0.19,0.67)$ & $55 \%$ & 0.001 \\
\hline $\mathrm{IHD}$ & 5 & {$[20,25,28,31,32]$} & 384 & $0.27(0.11,0.66)$ & $50 \%$ & 0.004 \\
\hline $\mathrm{CRRT} / \mathrm{IHD}$ & 2 & {$[17,27]$} & 427 & $0.53(0.15,1.86)$ & $89 \%$ & 0.32 \\
\hline \multicolumn{7}{|c|}{ Subgroup analysis: the relationship between study design and mortality } \\
\hline RCTs & 5 & {$[17,18,23,25,33]$} & 426 & $0.41(0.14,1.24)$ & $74 \%$ & 0.11 \\
\hline Cohort studies & 10 & {$[19,20,24,26-32]$} & 1053 & $0.33(0.23,0.46)$ & $15 \%$ & $<0.00001$ \\
\hline \multicolumn{7}{|c|}{ Subgroup analysis: the relationship between AKI classification on the basis of 2012 KDIGO criteria and mortality } \\
\hline KDIGO 1 & 7 & {$[18,19,23,25,27,29,30]$} & 762 & $0.40(0.23,0.69)$ & $46 \%$ & 0.001 \\
\hline KDIGO 2 & 2 & {$[32,33]$} & 99 & $0.04(0.01,0.15)$ & $0 \%$ & $<0.00001$ \\
\hline KDIGO 3 & 2 & {$[24,26]$} & 125 & $0.31(0.14,0.66)$ & $0 \%$ & 0.003 \\
\hline Unclassified & 4 & {$[17,20,28,31]$} & 493 & $0.66(0.41,1.07)$ & $23 \%$ & 0.09 \\
\hline
\end{tabular}

Abbreviations: RRT renal replacement therapy, $A K I$ acute kidney injury, $R C T$ randomized controlled trials, $O R$ odds ratio, $C l$ confidence interval, ICU intensive care unit, CRRT continuous renal replacement therapy, IHD Intermittent hemodialysis, LOS length of stay, MD, mean difference, KDIGO Kidney Disease: Improving Global Outcomes

RRT (OR 0.36; 95\% CI 0.23 to $0.57 ; I^{2} 60 \%$ ) (Fig. 3). Eight of the included articles showed that the ICU LOS (MD -2.50 days; $95 \%$ CI -3.53 to $-1.47 ; I^{2}$, 88\%) (Table 3) and hospital LOS (MD -0.69 days; $95 \%$ CI -1.13 to -0.25 ; $I^{2} 88 \%$ ) (Table 3) were also significantly decreased in early RRT, respectively, five included articles also showed that RRT duration was similarly decreased (MD -1.18 days; $95 \%$ CI -2.26 to $-0.11 ; I^{2}$ 69\%) (Table 3). It was necessary to perform subgroup analysis to increase the reliability of the results and clarify the source of the high heterogeneity that we identified.

\section{Subgroup analysis of early RRT and mortality}

A subgroup analysis based on different time periods to initiate "early and late" RRT included thirteen articles $[17-20,23-26,28-30,32,33]$ (Table 3), while one of the excluded article was not referred to time cutoffs [31], the other was the only one categorized to the group of 72 hours resulted in there was no comparability [27]. The outcomes of when to start early RRT were that in AKI after cardiac surgery, the incidence of mortality was significantly decreased by early initiation of RRT within 12 hours (OR 0.23 ; 95\% CI 0.08 to $0.63 ; I^{2} 73 \%$ ) and within 24 hours
(OR 0.52; 95\% CI 0.28 to $0.95 ; I^{2} 58 \%$ ) compared to initiation within 48 hours (OR 0.43 ; 95\% CI 0.17 to $1.09 ; I^{2}$ $15 \%)$. In other words, early RRT initiation within 24 hours significantly reduced mortality compared to initiation after 24 hours in patients with AKI post cardiac surgery.

We also analyzed a subgroup based on RRT modality (Table 3): the impact of RRT modality on mortality was that the modality, whether continuous RRT (CRRT) (OR 0.36; 95\% CI 0.19 to $\left.0.67 ; I^{2} 55 \%\right)$ or intermittent hemodialysis (IHD) (OR 0.27; $95 \%$ CI 0.11 to $0.66 ; I^{2} 50 \%$ ), had no effect on mortality in patients with AKI post cardiac surgery.

Furthermore, in another subgroup analysis based on study design (Table 3), in cohort studies there was a statistically significant decrease in mortality among patients who received early RRT (OR 0.33 ; $95 \%$ CI 0.23 to 0.46 ; $I^{2} 15 \%$ ), while the decrease in mortality in the RCTs (OR $0.41 ; 95 \%$ CI 0.14 to $1.24 ; I^{2} 74 \%$ ) was not statistically significant.

Finally, there was insignificant statistics in the subgroup of AKI classification (Table 3), the outcomes of different classifications on AKI dignosis impacted on the mortality as following KDIGO 1 (OR 0.40; 95\% CI 0.23 to $0.69 ; I^{2} 46 \%$ ), KDIGO 2 (OR 0.04; 95\% CI 0.01 to 
$0.15 ; I^{2} 0 \%$ ), KDIGO 3 (OR 0.31; 95\% CI 0.14 to 0.66 ; $I^{2} \quad 0 \%$ ) and unclassified (OR $0.66 ; 95 \%$ CI 0.41 to 1.07; $\left.I^{2} 23 \%\right)$.

\section{Sensitivity analysis and publication bias}

Sensitivity analysis indicated that the meta-analysis has low sensitivity and high stability in analysis of patients with AKI who had undergone cardiac surgery, which is demonstrated in Fig. 4. The Egger and Begg test funnel plots were used to explore publication bias (Fig. 5), the Egger linear regression test $(P>0.062)$ and the Begg rank correlation test $(P r>|z|=0.113)$, which provided no evidence of substantial publication bias in this meta-analysis.

\section{Sources of heterogeneity and meta-regression}

We performed meta-regression to investigate the sources of heterogeneity. The association between early RRT initiation and mortality was not influenced by year of publication $(P=0.949)$, either in study design $(P=0.114)$, RRT modality $(P=0.366)$ or a late RRT mortality rate $\geq 50 \%(P=0.087)$. Stratification of studies according to the definition of AKI showed no impact on mortality when early and late RRT criteria were defined on the basis of time cutoffs and categorized by urine output, creatinine and blood urea $(P=0.541)$.

\section{Discussion}

In the present meta-analysis of 15 articles involving 1479 adult patients with AKI who underwent cardiac surgery, we found that postoperative administration of early RRT decreased mortality and reduced the ICU LOS, hospital LOS and duration of RRT. Postoperative AKI is a common complication; the risk of death associated with AKI is proportional to its severity, with the highest rate in patients requiring hemodialysis post cardiac surgery [34-36], therefore, it is urgent that we distinguish AKI from the multitudinous complications and deal with it. In our current analysis, positive renal protective actions like initiating early RRT efficiently decreased the mortality due to AKI after cardiac surgery. The advantages for early RRT might be in decreasing the occurrence of life-threatening complications such as uremia, acidosis, volume overload and hyperkalemia. Interventions that attain the balance of solute clearance and fluid before progression to more serious disease also effectively attenuate kidney-specific and non-kidney organ injury when compared to late RRT.

However, there were also passive or controversial studies pertaining to the effect of early RRT, such as some studies that suggested that it was not necessary for clinicians to perform early RRT. Some were opposed to early RRT because it could expose patients to potential harms such as hemorrhage, bacteremia, thrombosis, intradialytic hypotension, clearance of trace elements and hypersensitivity to the extracorporeal circuit or antibiotics, which could lead to added resource utilization [37]. Our analysis produced the primary outcome that the initiation of early RRT showed evidence of survival advantages compared to late RRT. What is more, in our second outcome we found that early RRT initiation shortened the ICU LOS, hospital

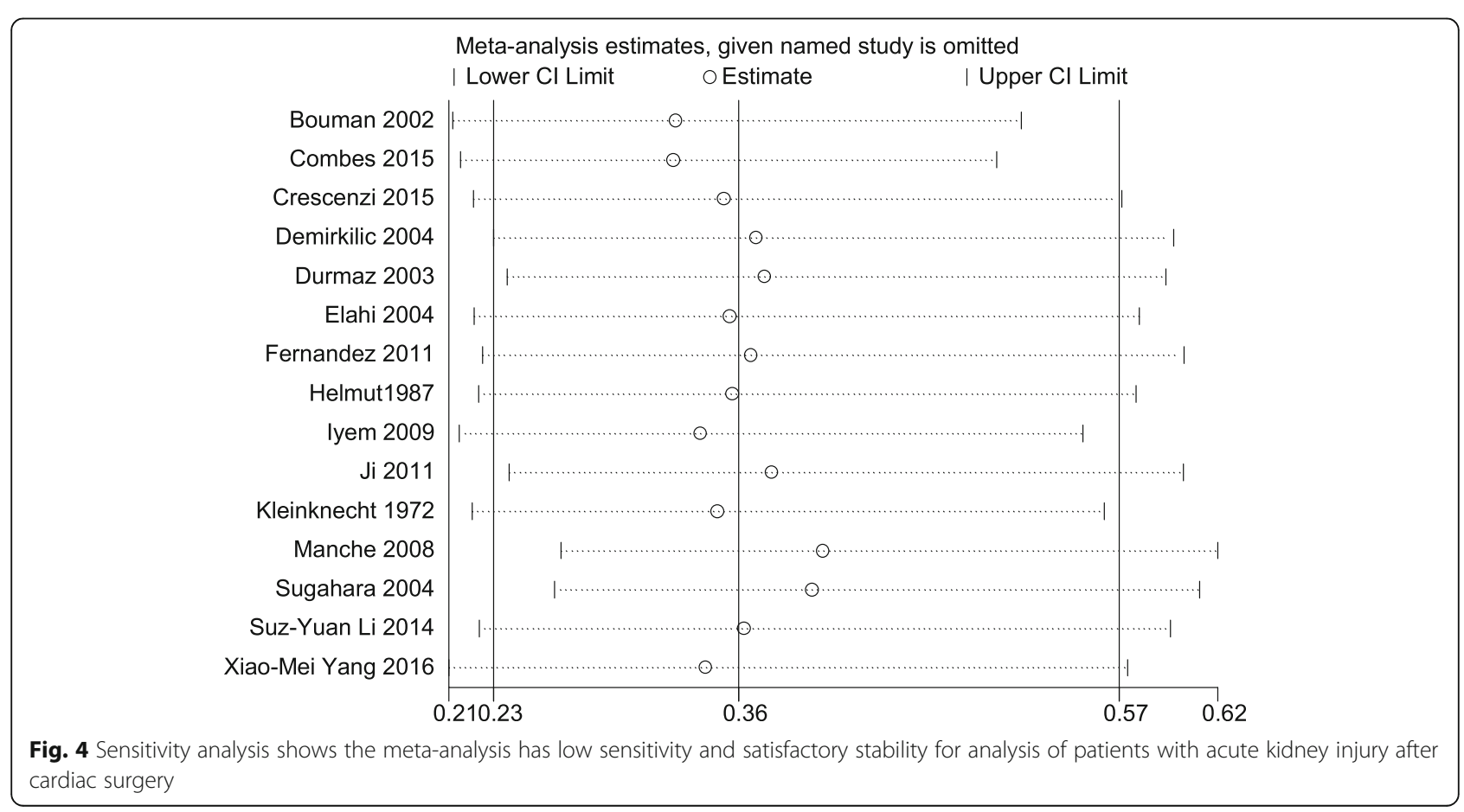



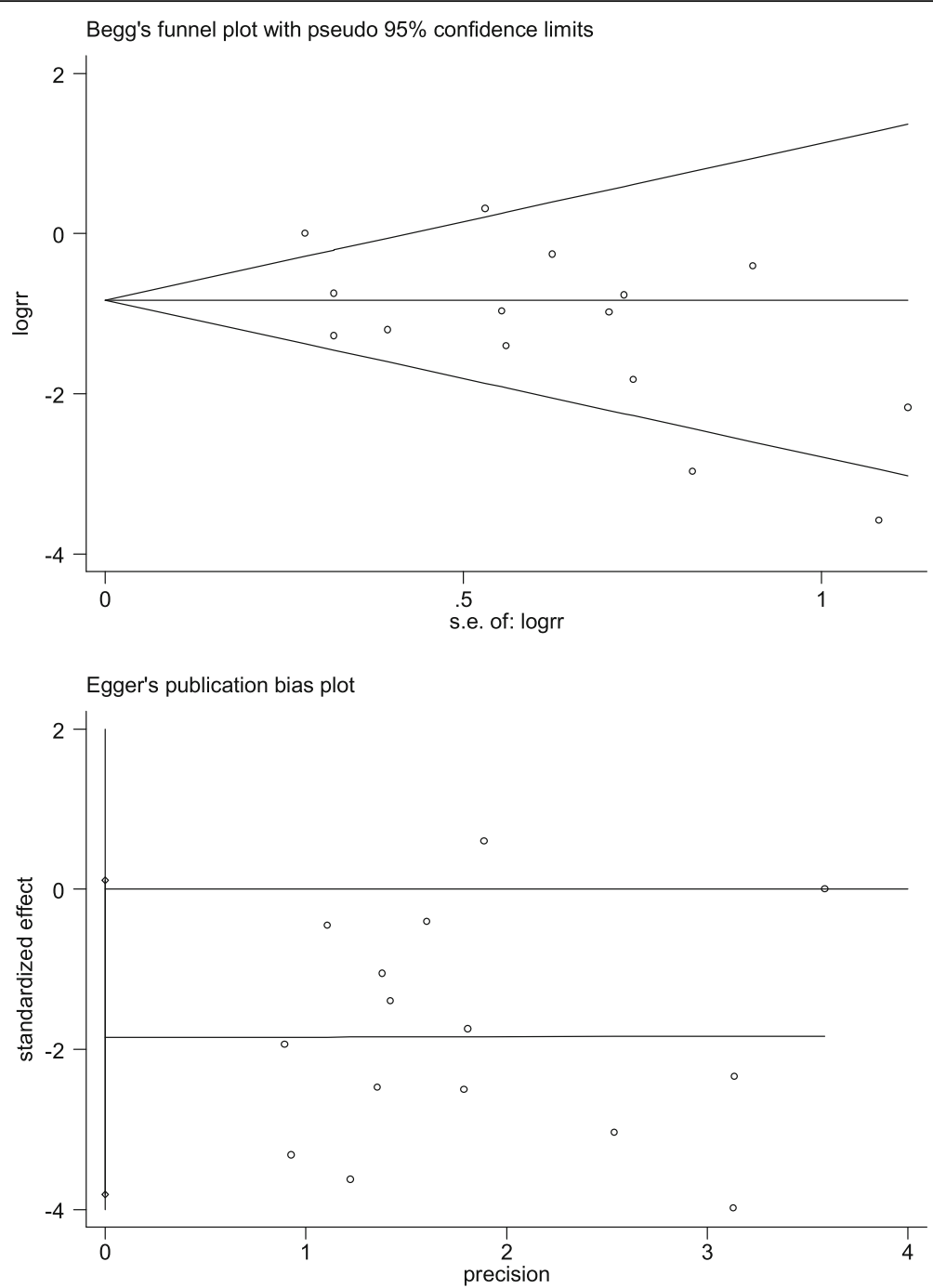

Fig. 5 Publication bias according to Egger and Begg test funnel plots

LOS and duration of RRT. Furthermore, in the subgroup analysis, early RRT initiation within 24 hours was associated with low mortality when compared to RRT initiation after 24 hours in patients with AKI post cardiac surgery.

To explore the sources of the heterogeneity, first, we performed the subgroup analysis based on RRT modality and study design, respectively, which were not statistically significant. Second, we completed sensitivity analysis, which indicated that our meta-analysis had low sensitivity and satisfactory stability. Egger and Begg test funnel plots showed no publication bias in this meta-analysis: however, despite this we should not jump rashly to the conclusion of no publication bias, because the $P$ value for the Egger linear regression test $(P>0.062)$ was close to 0.05 . Last but not least, meta-regression included five variables that were not heterogenous. As for the high heterogeneity of ICU LOS, hospital LOS and duration of RRT, not all the articles provided original data for the mean and standard deviation, which might affect the heterogeneity.

There were several potential limitations in the metaanalysis. First, the definition of early RRT criteria was different in the included studies, which may have led to the difference in the requirement for RRT and the subsequent therapeutic results in patients with cardiac-surgeryrelated AKI [38]. Second, the sample size in each of the included five RCTs is relatively small, so it is necessary to perform large, multi-centered RCTs to support the present results. Although the AKIKI trial [39] and ELAIN trial [40] were performed in critically ill patients, the standard definition of AKI and indication for RRT may be applied to patients with AKI post cardiac surgery. Third, there are limitations to retrospective trials such as the sample size, and therefore they may not be representative and the risk of recall bias may be higher. 


\section{Conclusions}

Cardiac-surgery-associated AKI probably benefits from early RRT initiation, which would decrease 28-day mortality and shorten the ICU LOS, hospital LOS and duration of RRT. What is more, early RRT initiation within 24 hours showed evidence of a survival advantage when compared to initiation after 24 hours in patients with AKI post cardiac surgery.

\section{Abbreviations}

AKI: Acute kidney injury; Cl: Confidence interval; Cr: Creatinine; CRRT: Continuous renal replacement therapy; h: Hours; ICU: Intensive care unit; IHD: Intermittent hemodialysis; KDIGO: Kidney Disease: Improving Global Outcomes; LOS: Length of stay; MD: Mean difference; NOS: Newcastle-Ottawa Scale; NR: Not reported; OR: Odds ratio; RCTs: Randomized controlled trials; RRT: Renal replacement therapy; UOP: Urine output

\section{Acknowledgements}

Not applicable.

\section{Funding}

This work was supported by the National Natural Science Foundation of China (number H0517/81560132) and the Supporting Project for the Foregoers of Main Disciplines of Jiangxi Province (No. 20162BCB22023).

\section{Availability of data and materials}

The data are available for review on request.

\section{Authors' contributions}

$\mathrm{HZ}$ performed the literature search, reviewed articles, completed the data analysis using the Review Manager (version 5.3) and STATA statistical software (version 12.0) and wrote the manuscript. QH reviewed the articles and provided secondary reviews during the manuscript preparation. GX designed the analysis and revised the manuscript. All the authors read and approved the final version of the manuscript

\section{Competing interests}

The authors declare that they have no competing interests.

\section{Consent for publication}

Not applicable.

\section{Ethics approval and consent to participate}

Not applicable.

\section{Publisher's Note}

Springer Nature remains neutral with regard to jurisdictional claims in published maps and institutional affiliations.

\section{Author details}

${ }^{1}$ Medical Center of the Graduate School, Nanchang University, Nanchang, People's Republic of China. ${ }^{2}$ Science and Technology College, Jiangxi University of Traditional Chinese Medicine, Nanchang, People's Republic of China. ${ }^{3}$ Department of Nephrology, the Second Affiliated Hospital of Nanchang University, No. 1, Minde Road, Donghu District, Nanchang 330006, People's Republic of China.

\section{Received: 9 November 2016 Accepted: 9 May 2017}

\section{Published online: 17 June 2017}

\section{References}

1. Ryckwaert F, Boccara G, Frappier JM, Colson PH. Incidence, risk factors, and prognosis of a moderate increase in plasma creatinine early after cardiac surgery. Crit Care Med. 2002;30:1495-8.

2. Cooper WA, O'Brien SM, Thourani VH, Guyton RA, Bridges CR, Szczech LA, et al. Impact of renal dysfunction on outcomes of coronary artery bypass surgery: results from the Society of Thoracic Surgeons National Adult Cardiac Database. Circulation. 2006;113:1063-70.
3. Siddiqui NF, Coca SG, Devereaux PJ, Jain AK, Li L, Luo J, et al. Secular trends in acute dialysis after elective major surgery-1995 to 2009. CMAJ. 2012;184:1237-45

4. Mehta RL, Kellum JA, Shah SV, Molitoris BA, Ronco C, Warnock DG, Levin A. Acute Kidney Injury Network: report of an initiative to improve outcomes in acute kidney injury. Crit Care. 2007;11:R31.

5. Waikar SS, Curhan GC, Wald R, McCarthy EP, Chertow GM. Declining mortality in patients with acute renal failure, 1988 to 2002. J Am Soc Nephrol. 2006;17:1143-50.

6. Xue JL, Daniels F, Star RA, Kimmel PL, Eggers PW, Molitoris BA, et al. Incidence and mortality of acute renal failure in Medicare beneficiaries, 1992 to 2001. J Am Soc Nephrol. 2006;17:1135-42.

7. Bellomo R, Ronco C, Kellum JA, Mehta RL, Palevsky P. Acute renal failure definition, outcome measures, animal models, fluid therapy and information technology needs: the Second International Consensus Conference of the Acute Dialysis Quality Initiative (ADQI) Group. Crit Care. 2004;8:R204-12.

8. Chertow GM, Burdick E, Honour M, Bonventre JV, Bates DW. Acute kidney injury, mortality, length of stay, and costs in hospitalized patients. J Am Soc Nephrol. 2005;16:3365-70.

9. Filsoufi F, Rahmanian PB, Castillo JG, Silvay G, Carpentier A, Adams DH. Predictors and early and late outcomes of dialysis-dependent patients in contemporary cardiac surgery. J Cardiothorac Vasc Anesth. 2008;22:522-9.

10. Thakar CV, Worley S, Arrigain S, Yared JP, Paganini EP. Improved survival in acute kidney injury after cardiac surgery. Am J Kidney Dis. 2007;50:703-11.

11. Ferguson TJ, Hammill BG, Peterson ED, DeLong ER, Grover FL. A decade of change-risk profiles and outcomes for isolated coronary artery bypass grafting procedures, 1990-1999: a report from the STS National Database Committee and the Duke Clinical Research Institute. Society of Thoracic Surgeons. Ann Thorac Surg. 2002;73:480-9. 489-490.

12. Gaffney AM, Sladen RN. Acute kidney injury in cardiac surgery. Curr Opin Anaesthesiol. 2015;28:50-9.

13. Liu Y, Davari-Farid S, Arora P, Porhomayon J, Nader ND. Early versus late initiation of renal replacement therapy in critically ill patients with acute kidney injury after cardiac surgery: a systematic review and meta-analysis. J Cardiothorac Vasc Anesth. 2014;28:557-63.

14. Seabra VF, Balk EM, Liangos O, Sosa MA, Cendoroglo M, Jaber BL. Timing of renal replacement therapy initiation in acute renal failure: a meta-analysis. Am J Kidney Dis. 2008:52:272-84.

15. Wierstra BT, Kadri S, Alomar S, Burbano X, Barrisford GW, Kao RL. The impact of "early" versus "late" initiation of renal replacement therapy in critical care patients with acute kidney injury: a systematic review and evidence synthesis. Crit Care. 2016;20:122.

16. Wang C, LV LS, Huang H, Guan J, Ye Z, Li S, et al. Initiation time of renal replacement therapy on patients with acute kidney injury: a systematic review and meta-analysis of 8179 participants. Nephrology (Carlton). 2017; 22:7-18

17. Combes A, Brechot N, Amour J, Cozic N, Lebreton G, Guidon C, et al. Early high-volume hemofiltration versus standard care for post-cardiac surgery shock. The HEROICS Study. Am J Respir Crit Care Med. 2015;192:1179-90.

18. Crescenzi G, Torracca L, Pierri MD, Rosica C, Munch C, Capestro F. 'Early' and 'late' timing for renal replacement therapy in acute kidney injury after cardiac surgery: a prospective, interventional, controlled, single-centre trial. Interact Cardiovasc Thorac Surg. 2015;20:616-21.

19. Li SY, Yang WC, Chuang CL. Effect of early and intensive continuous venovenous hemofiltration on patients with cardiogenic shock and acute kidney injury after cardiac surgery. J Thorac Cardiovasc Surg. 2014;148:1628-33.

20. Yang XM, Tu GW, Gao J, Wang CS, Zhu DM, Shen B, et al. A comparison of preemptive versus standard renal replacement therapy for acute kidney injury after cardiac surgery. J Surg Res. 2016;204:205-12.

21. Stang A. Critical evaluation of the Newcastle-Ottawa scale for the assessment of the quality of nonrandomized studies in meta-analyses. Eur J Epidemiol. 2010;25:603-5.

22. Higgins JP, Thompson SG, Deeks JJ, Altman DG. Measuring inconsistency in meta-analyses. BMJ. 2003;327:557-60.

23. Bouman CS, Oudemans-Van SH, Tijssen JG, Zandstra DF, Kesecioglu J. Effects of early high-volume continuous venovenous hemofiltration on survival and recovery of renal function in intensive care patients with acute renal failure: a prospective, randomized trial. Crit Care Med. 2002;30:2205-11.

24. Demirkilic U, Kuralay E, Yenicesu M, Caglar K, Oz BS, Cingoz F, et al. Timing of replacement therapy for acute renal failure after cardiac surgery. J Card Surg. 2004;19:17-20. 
25. Durmaz I, Yagdi T, Calkavur T, Mahmudov R, Apaydin AZ, Posacioglu H, et al. Prophylactic dialysis in patients with renal dysfunction undergoing on-pump coronary artery bypass surgery. Ann Thorac Surg. 2003;75:859-64.

26. Elahi MM, Lim MY, Joseph RN, Dhannapuneni RR, Spyt TJ. Early hemofiltration improves survival in post-cardiotomy patients with acute renal failure. Eur J Cardiothorac Surg. 2004;26:1027-31.

27. Garcia-Fernandez N, Perez-Valdivieso JR, Bes-Rastrollo M, Vives M, Lavilla J, Herreros J, Monedero P. Timing of renal replacement therapy after cardiac surgery: a retrospective multicenter Spanish cohort study. Blood Purif. 2011;32:104-11.

28. Lange HW, Aeppli DM, Brown DC. Survival of patients with acute renal failure requiring dialysis after open heart surgery: early prognostic indicators. Am Heart J. 1987;113:1138-43.

29. Iyem $H$, Tavli M, Akcicek F, Buket S. Importance of early dialysis for acute renal failure after an open-heart surgery. Hemodial Int. 2009:13:55-61.

30. Ji Q, Mei Y, Wang X, Feng J, Cai J, Zhou Y, et al. Timing of continuous veno-venous hemodialysis in the treatment of acute renal failure following cardiac surgery. Heart Vessels. 2011;26:183-9.

31. Kleinknecht D, Jungers P, Chanard J, Barbanel C, Ganeval D. Uremic and non-uremic complications in acute renal failure: Evaluation of early and frequent dialysis on prognosis. Kidney Int. 1972;1:190-6.

32. Manche A, Casha A, Rychter J, Farrugia E, Debono M. Early dialysis in acute kidney injury after cardiac surgery. Interact Cardiovasc Thorac Surg. 2008;7:829-32.

33. Sugahara S, Suzuki H. Early start on continuous hemodialysis therapy improves survival rate in patients with acute renal failure following coronary bypass surgery. Hemodial Int. 2004;8:320-5.

34. Hobson CE, Yavas S, Segal MS, Schold JD, Tribble CG, Layon AJ, Bihorac A. Acute kidney injury is associated with increased long-term mortality after cardiothoracic surgery. Circulation. 2009; 119:2444-53.

35. Metnitz PG, Krenn CG, Steltzer H, Lang T, Ploder J, Lenz K, et al. Effect of acute renal failure requiring renal replacement therapy on outcome in critically ill patients. Crit Care Med. 2002;30:2051-8.

36. Che M, Li Y, Liang X, Xie B, Xue S, Qian J, et al. Prevalence of acute kidney injury following cardiac surgery and related risk factors in Chinese patients. Nephron Clin Pract. 2011;117:C305-11.

37. Gibney RT, Bagshaw SM, Kutsogiannis DJ, Johnston C. When should renal replacement therapy for acute kidney injury be initiated and discontinued? Blood Purif. 2008:26:473-84.

38. O'Hare AM, Feinglass J, Sidawy AN, Bacchetti P, Rodriguez RA, Daley J, et al. Impact of renal insufficiency on short-term morbidity and mortality after lower extremity revascularization: data from the Department of Veterans Affairs' National Surgical Quality Improvement Program. J Am Soc Nephrol. 2003;14:1287-95.

39. Gaudry S, Hajage D, Schortgen F, Martin-Lefevre L, Pons B, Boulet E, et al. Initiation strategies for renal-replacement therapy in the intensive care unit. N Engl J Med. 2016;375:122-33.

40. Zarbock A, Kellum JA, Schmidt C, Van Aken H, Wempe C, Pavenstadt H, et al. Effect of early vs delayed initiation of renal replacement therapy on mortality in critically ill patients with acute kidney injury: the ELAIN randomized clinical trial. JAMA. 2016;315:2190-9.

\section{Submit your next manuscript to BioMed Central and we will help you at every step:}

- We accept pre-submission inquiries

- Our selector tool helps you to find the most relevant journal

- We provide round the clock customer support

- Convenient online submission

- Thorough peer review

- Inclusion in PubMed and all major indexing services

- Maximum visibility for your research

Submit your manuscript at www.biomedcentral.com/submit 